\title{
A district confidential enquiry into deaths due to
} asthma

\author{
N J Wareham, B D W Harrison, P F Jenkins, J Nicholls, D E Stableforth
}

\begin{abstract}
Background-The aim was to establish a continuing district based confidential enquiry into deaths from asthma.

Methods-A confidential enquiry was conducted in an English health district. Subjects comprised 24 residents of the Norwich health district aged between 16 and 65 years who had died between 1988 and 1991 with asthma as the principal cause of death.
\end{abstract}

Results-Twenty one of the patients $(88 \%)$ died away from hospital. Overall the routine asthma management was appropriate in all respects in only four patients. In five cases the drug treatment was considered inappropriate, in 10 cases (42\%) there was no written evidence that the patient had received advice and education, and only six cases had a written management plan. In 17 patients (71\%) the fatal attack of asthma developed rapidly (in under three hours). The medical care during the final attack was found to have been inappropriate in six cases. Seventeen cases $(71 \%)$ had psychological or social factors that were considered to have been of potential importance.

Conclusions-This study has shown the feasibility of organising a confidential enquiry into asthma deaths within a health district. The distinguishing features of such an enquiry are that it is continuing, that the quality of care given to those patients who died is compared against a recognised standard, and that there is a structured system for feeding back the conclusions of the enquiry to the local medical community.

(Thorax 1993;48:1117-1120)

Epidemiological evidence of temporal ${ }^{1}$ and geographical $^{2}$ variation in asthma mortality can be interpreted in many different ways. The possibilities include variations in the use of asthma as a diagnosis or in the probability of using asthma as the principal cause of death on the death certificate. Changes in the prevalence and severity of disease could account for the variation in asthma mortality, as could the possibility that certain therapeutic interventions have associated adverse effects. Another consideration is the quality of current asthma care; the degree to which therapeutic interventions are optimally effective.
Although direct measurement of the quality of care and its association with health outcomes in patients with asthma is methodologically possible, the relative rarity of asthma deaths has not made this an efficient approach. Therefore, previous studies have concentrated on detailed examination of the quality of care given to those patients who had died of asthma. In the 1980s two large studies of this kind suggested that a high proportion of deaths were potentially preventable. $^{34}$ This finding has led to the inclusion of asthma deaths in the lists of conditions that are theoretically amenable to medical intervention ${ }^{5}$ and which have been proposed as possible indicators of the quality of care. ${ }^{6}$ Although these extended case series were important in raising the question of the association of quality with adverse events in patients with asthma, they were not designed to be part of a continuing quality improvement programme. This paper describes the establishment, evolution, and initial results of a confidential enquiry into asthma deaths. This enquiry has features that distinguish it from a simple case series. Firstly, the quality of care was compared against accepted and objective quality criteria, thus reducing the possibility of observer bias. Secondly, the programme was established to be a continuing rather than a one off study, and thus as far as possible the work required by the enquiry has been incorporated into the regular activities of those involved. Thirdly, the focus of attention of the study has been broad, so as to encompass all those concerned with the care of patients with asthma. Finally, the collective results have been fed back to the entire medical community with the emphasis on the elimination of systematic errors, rather than on the detection of aberrant individual clinical practice. It is thus in keeping with the notion of continuous quality improvement. ${ }^{7}$ A system built on individualised feedback to those clinicians whose patients had died would have been unproductive as it would have generated defensiveness, impeding rather than facilitating improvement.

\section{Methods}

Because a confidential enquiry can be threatening to individual clinicians unless it is widely understood that the purpose is to identify systematic errors rather than to detect aberrant individual clinical practice, the various parts of the enquiry were introduced in a staged fashion in order to maxi- 
mise collaboration and minimise conflict. The methods section of this paper therefore not only describes the final design of the enquiry, but also the various stages of evolution that it underwent during its establishment.

The decision to construct a continuing rather than a one off study led to efforts from the early planning stages to incorporate the work of the enquiry into the routine activities of those involved, rather than to rely on external support. This necessitates local recognition of the need for such an enquiry and a considerable degree of cross institutional collaboration.

The names of all those patients resident in the Norwich health district who had died between 1988 and 1991, and in whom there was any mention of asthma (International Classification of Disease 9th revision code 493) in part one of the death certificate, were obtained from the Norwich death system, a locally based multicause coding system of the weekly Registrar death returns. Only those cases aged between 16 and 65 years were included because of the reported imprecision of death certification in asthma in elderly patients. ${ }^{8}$ Permission to carry out the study protocol was received from the Norwich District ethics committee and from the local medical committee.

For deaths in 1988 and 1989 only the hospital and general practice records were used to obtain clinical information, which was abstracted on to a questionnaire developed from those used in the British Thoracic Association (BTA) and New Zealand confidential enquiries. ${ }^{34}$ For deaths that occurred in 1990 onwards, a system for interviewing the next of kin of the deceased patient was introduced. The relatives of those patients who had died in 1988 and 1989 were not interviewed because of the time that would have lapsed since death, which would have affected recall of the detail of the events leading up to death. The interviews were conducted by one of us (JN) with the questionnaire developed from the BTA and New Zealand studies. In 1992 interviews with general practitioners were started, to collect clinical information on the routine care of the patient that could not be obtained from the general practice notes (the results of deaths from 1992 are not considered in this paper). These interviews were conducted by a general practitioner from an adjacent health authority.

The objective data obtained from the interviews with the relatives and from the written records were assessed by a panel of three chest physicians, two from the Norwich health district and one external assessor. They were asked to discuss the presence or absence of patient related factors, the appropriateness of the routine medical care, the circumstances of the final attack, and the appropriateness of the medical care during the final attack. The quality of care given to the patients was assessed with the 1990 national guidelines for the management of chronic persistent and acute severe asthma. ${ }^{910}$ All these data were recorded on to coded data sheets to protect the anonymity of the patients and physicians.

The results and general lessons from the 공 enquiry were fed back to the entire local med- $\frac{0}{0}$ ical community in a series of written reports. ? These were sent to all general practitioners in $\overrightarrow{\vec{F}}$ the district with a covering note from the $\frac{\overrightarrow{0}}{0}$ Director of Public Health creating linkage $\frac{c}{\sigma}$ between the results of the confidential $\frac{\bar{\omega}}{5}$ enquiry and the recently published district $\stackrel{\mathbb{Q}}{\Omega}$ guidelines for the management of asthma. The first report was timed to be received by the general practitioners within two weeks of the guidelines. This form of feedback was $\vec{\omega}$ implemented to enhance the effects of the guidelines as evidence suggests that by them- $\vec{x}$ selves guidelines have a limited impact on $\frac{\infty}{\infty}$ clinical practice. ${ }^{11}$ Feedback to junior hospital $\rightarrow$ staff was verbal.

\section{Results}

INITIAL RESULTS OF THE ENQUIRY

Twenty five eligible cases were identified. One patient was excluded from the analysis $\frac{\Phi}{3}$ because the review panel considered that his $\underset{\mathbb{D}}{\mathcal{D}}$ death was not attributable to asthma. There were 17 women and seven men, and the $₫$ mean age at death was 45.4 years. Twenty one $(88 \%)$ of the patients died at home or were dead on arrival at hospital. Postmortem examinations were conducted in $17(71 \%)$ and all showed changes in the lungs typical of fatal asthma. The panel graded the asthma as $\cong$ severe in 17 patients, moderate in six, and $\overrightarrow{\vec{O}}$ was unable to grade one because of insufficient information.

Psychological or social factors that may have been important in the death of the patient were discovered in 17 cases $(71 \%)$. These included social isolation, abuse when:the patient was a child, neurotic illness, marital or legal problems, and alcohol abuse. The $\delta$ routine treatment of the patients was graded as appropriate in 19 cases $(79 \%)$. In all five of $\bigcirc$ the cases in which there were major deficien- $\rightarrow$ cies of care there was evidence that oral or inhaled steroids had either not been pre- $N$ scribed or had been prescribed in inappropriate doses. The panel assessment of three of these cases suggested that they should have ${ }^{\omega}$ been referred earlier to a specialist chest physician. The use of peak flow measurements was deemed to have been adequate in 15 patients $(65 \%)$, whereas in the remainder peak flow was either not measured at all orō was not monitored often enough given the clinical state of the patient. In 10 cases $(42 \%) \stackrel{\overparen{D}}{\mathbb{Q}}$ there was no written evidence that the patient $\bar{\sigma}$ had received advice and education about their asthma, although in most instances there waso additional evidence to suggest that the patients had received advice but that this had? not been documented. Only six of the cases? had a written management plan, although it should be noted that many of these patients were being treated at a time when such plans were not in widespread use. Combining the 
assessment of the appropriateness of the drug treatment with the occurrence of appropriate monitoring and education suggests that overall only four patients received routine care that was appropriate in all respects.

The final attack developed rapidly (in under three hours) in 17 cases of the 22 in which this could be assessed. The medical care given to the patient during the final attack was appropriate in 18 cases (75\%). The deficiencies in care that were noted were varied but included premature discharge from hospital, delayed admission to hospital, and underestimation of the severity of the attack. Seven patients experienced delay in receiving medical care. In two of these cases the panel noted problems in communicating for help. Neither of these patients had a private telephone, and in one case the patient was unable to summon help because the nearest public telephone had been vandalised. In the five remaining cases the delay was attributable to the actions of the patient or the patient's relatives.

\section{OUTCOME OF INSTITUTING AN ENQUIRY}

This study has shown that it is feasible to conduct an enquiry into asthma deaths at district level. The major findings that have been of local relevance relate to the appropriateness of medical care, the importance of psychological and social factors, and questions of accessibility to medical care. Although most cases were deemed to have received appropriate drug treatment, inhaled and oral steroids were underused and there was evidence that some patients had not been adequately monitored.

The failure of 21 of the 24 patients to reach hospital is a matter of concern in a large rural health district in which transit times between home and hospital may be considerable. Previous studies have suggested that access to care for people with asthma may be important in rural areas ${ }^{12} 13$ and have highlighted the need to pay careful attention to the prehospital recognition and treatment of acute asthma. ${ }^{14}$ The occurrence in two patients of serious delay in obtaining medical assistance during the final attack because of their inability to call for help, has reiterated the importance for people with life threatening asthma of having a means of communicating for assistance. ${ }^{15}$

Four patients failed to summon help even though there was evidence of deterioration in their clinical condition. This re-emphasises the importance of the role of the patient and their family in recognising and responding to a severe asthma attack. It is possible that the psychological and social factors that are of aetiological importance in deaths due to asthma mediate their effect by altering a person's capacity to respond appropriately.

The results of this enquiry have contributed to various local initiatives including the establishment of a joint clinic between a respiratory physician and a psychiatrist treating adolescents, the referral of patients with psychological problems to our health visitor for home visits and support, and the training of emergency paramedical staff in the treatment and monitoring of patients with severe asthma. In the light of the rapid onset of the asthma attack in many of the cases and the death of most away from hospital, educational efforts in the hospital clinics are now targeted at the relatives of high risk patients as well as the patients themselves. Lastly, the local social services department has agreed to fund the cost of a telephone for the homes of those "at risk" patients with asthma who would otherwise be unable to afford one.

\section{Discussion}

A confidential enquiry is a hybrid method, combining aspects of an extended case series and a quality improvement mechanism. Previous confidential enquiries into deaths due to asthma have fulfilled the role of an extended case series, but did not set out to act as a formal part of quality improvement. The distinguishing features of this confidential enquiry are the use of explicit accepted standards, the structured system of local feedback, and the continuing rather than one off nature of the enquiry.

The successful introduction of the confidential enquiry into asthma deaths in Norwich is a testament to the widespread acceptance among the local medical community of the need to develop a method to monitor and investigate sentinel health events in an analogous way to other enquiries such as those into maternal ${ }^{16}$ or perioperative deaths. ${ }^{17}$ Although such enquiries are widely accepted as being instrumental in altering clinical and managerial practice and thereby improving outcome, definitive evidence of a causal relation between the introduction of an enquiry and improvement in health outcome is lacking. ${ }^{18}$ The effect of the introduction of the asthma confidential enquiry in Norwich may not be directly evident in a change in outcome because of the statistical problems involved in showing a change in an already very low mortality rate. Thus the solution to the problem of showing that the enquiry has been beneficial must be indirect, relying on evidence of changes to managerial and clinical processes and an overall trend towards a decrease in local asthma mortality. It is possible that the extension of the method to other districts and regions might generate sufficient numbers to more rigorously assess the effectiveness of the approach.

We think Dr P C Walker, Dr R M Badminton, Mrs M Clayton, and Mrs L Ward from the Department of Public Health Medicine, Norwich Health Authority for their help with this project.

1 Burney P. Asthma deaths in England and Wales 1931-85: evidence for a true increase in asthma mortality. $f$ Epidemiol Community Health 1988;42:316-20.

2 Holland WW (ed). European Community atlas of "avoidable death". Oxford: Oxford University Press, 1988.

3 The British Thoracic Association. Death from asthma in two regions of England. $B M \mathcal{F}$ 1982;285:1251-5.

4 Sears M, Rea H, Beaglehole R, Gillies JD, Holst PE, O'Donnell TV, et al. Asthma mortality in New Zealand: 
a two year national study. NZ Med f 1985;98:271-5.

5 Charlton JRH, Hartley RM, Silver R, Holland WW. Geographical variation in mortality from conditions amenable to medical intervention in England and Wales. Lancet 1983;i:691-6.

6 Rutstein DD, Berenberg W, Chalmers TC, Child CG, Fishman AP, Perrin EB. Measuring the quality of medical care: a clinical method. $N$ Engl $\mathcal{F}$ Med 1976;294: $582-8$.

7 Berwick DM. Continuous improvement as an ideal in health care. $N$ Engl F Med 1989;320:53-6.

8 The Research Committee of the British Thoracic Association. Accuracy of death certification in bronchial asthma. Thorax 1984;39:505-9.

9 The British Thoracic Society, The Royal College of Physicians Research Unit, The King's Fund Centre, The National Asthma Campaign. Guidelines for the management of asthma in adults: I-Chronic persistent asthma. BMF 1990;301:651-3.

10 The British Thoracic Society, The Royal College of Physicians Research Unit, The King's Fund Centre, The National Asthma Campaign. Guidelines for the management of asthma in adults: II-Acute severe asthma. BMF 1990;301:797-800.
11 Lomas J, Anderson GM, Domnick-Pierre K, Vayda E, Enkkin MW, Hannah WJ. Do practice guidelines guide practice? N Engl f Med 1989;321:1306-11.

12 Taytard A, Tessier JF, Gervais M, Gachie JP, Douet C, Kombou L, et al. Actual usage of medical facilities by asthmatics in two French rural settings: a preliminary study. Eur Respir F 1990;3:856-60.

13 Wilson JMG. Asthma deaths in Scotland 1965-1980. Scott Med f 1984;29:84-9.

14 Barriot P, Riou B. Prevention of fatal asthma. Chest 1987;92:460-6.

15 Ellis ME, Friend JA. How well do asthma clinic patient understand their asthma? Brf Dis Chest 1985;79:43-8.

16 The Department of Health. The report of the Confidential Enquiry into Maternal Deaths in England and Wales, 1982-84. London: HMSO, 1989.

17 Campling EA, Devlin HB, Hoile RW, Lunn JN. The repor of the National Confidential Enquiry into Perioperative Deaths. London: National Confidential Enquiry into Perioperative Deaths, 1992.

18 Elbourne D, Mutch L. Do locally based enquiries into perinatal mortality reduce the risk of perinatal death? In Smith $\mathrm{A}$, ed. Recent advances in community medicine. London: Churchill Livingstone, 1985. 